\title{
Correction to: Interoccurrence times and seismic hazard for upper-crustal volcanic chain earthquakes in El Salvador: are they Poissonian distributed?
}

\section{Walter Salazar ${ }^{1}$ (iD}

Received: 29 March 2021 / Accepted: 29 March 2021 / Published online: 8 April 2021

(c) Springer Nature B.V. 2021

\section{Correction to: Natural Hazards https://doi.org/10.1007/s11069-021-04640-w}

This correction stands to correct two discrepancies found in the original article. Readers should note the following:

1. In the Introduction the reference, Salazar et al. (2018) should be noted as Salazar et al. (2013). Since the first seismic hazard maps published by Algermissen et al. (1988) through Salazar et al. (2013).

2. In section, 3.1 Cumulative probabilities, Eq. 8 should be noted as:

Matching the left part of Eqs. 2 and 4 gives:

$$
1-e^{-\lambda t}=1-e^{-\alpha t^{\beta}}
$$

We noticed that the $\alpha$ coefficient for M 6.25-6.5 and M 6.5-7 in the Weibull model yields almost zero (see Table 2).

Publisher's Note Springer Nature remains neutral with regard to jurisdictional claims in published maps and institutional affiliations.

The original article can be found online at https://doi.org/10.1007/s11069-021-04640-w.

Walter Salazar

walter.salazar@catolica.edu.sv

1 Catholic University of El Salvador, UNICAES, Santa Ana, El Salvador 